\title{
ASPECTOS DO PENSAMENTO HISTORIOGRÁFICO MEDIEVAL NO MANUSCRITO Y-III-5 DA BIBLIOTECA DEL MONASTERIO DE SAN LORENZO DE EL ESCORIAL
}

\author{
ASPECTS OF THE MEDIEVAL HISTORIOGRAPHICAL \\ THOUGHT IN THE MS. Y-III-5 OF THE BIBLIOTECA DEL \\ MONASTERIO DE SAN LORENZO DE EL ESCORIAL
}

\author{
Luciano José Vianna \\ Universidade de Pernambuco/campus Petrolina
}

\begin{abstract}
Resumo: A escrita da história durante o Medievo legou uma diversidade de tipologias de fontes, as quais, embora apresentem funções específicas, também podem estar presentes em um mesmo objeto. Este é o caso do manuscrito YIII-5 da Real Biblioteca del Monasterio de San Lorenzo de El Escorial, o qual apresenta em seu conteúdo textual uma crônica, uma cronologia genealógica e um compêndio. Uma vez que foi composto por diferentes personagens, também apresenta uma diversidade de intencionalidades. Este artigo tem como objetivo não somente estabelecer a data de composição do manuscrito, mas também compreender o significado histórico do mesmo, abordando não somente as suas diferentes perspectivas (textual, codicológica e paleográfica), mas também relacionando as diversas informações encontradas em cada parte do mesmo de acordo com o contexto de composição.
\end{abstract}

Palavras-chave: Cronologia, genealogia, passado.
Abstract: The writing of history in the Middle Ages gave us a diversity of typologies of sources, which, however present different functions, also could be present in a same object. This is the case of MS. Y-III-5 of the Real Biblioteca del Monasterio de San Lorenzo de El Escorial, which present in his textual information a chronicle, a genealogical chronology, and a compendia. Furthermore, this object was composed by different characters, and, in this sense, present a diversity of intentionality. The aim of this article is not only to stablish the date of composition of the manuscript, but also to understand his historical meaning, highlighting not only his different perspectives (textual, codicological, and palaeographical), but also relating the several information founded in each part of the manuscript according to the context of composition.

Keywords: Chronology, Genealogy, Past. 


\section{Introdução}

Uma genealogia, uma das mais expressivas produções historiográficas elaboradas no Medievo, apresentava como principal característica o fato de relacionar o presente e o passado. ${ }^{1}$ Sua função era de vinculação imediata entre dois tempos distantes, os quais, uma vez textualizados, faziam parte de um mesmo contexto de justificativa e legitimação, muitas das vezes política. Ao refletir sobre a interação entre História e Política no Medievo, Jaume Aurell nos apresenta de forma sucinta a importância desta relação:

A importância da historiografia vem determinada por sua condição de legitimação do presente através da aproximação intencional ao passado. (...). A transcendência da historiografia medieval vem em boa medida determinada pelo que a tradição possui neste período, no qual cada modificação do presente deveria ser confrontada com a tradição recebida do passado. A realidade do presente e os planos do futuro se fundamentavam na fundação do passado. Neste contexto, a intencionalidade e a função da historiografia é clara: fundir em uma mesma realidade o passado e o presente, a tradição e a inovação, as velhas e as novas formas de governo. A legitimação das formas políticas do momento será maior na medida em que se consiga demonstrar que há uma só direção na corrente histórica que conecta o passado com o presente, ou seja, que a situação atual se vincula diretamente com as origens míticas. (...). A historiografia deste período costuma estar condicionada por uma notável intencionalidade política, que leva a 'usar' o passado. Porém, tratase de uma manipulação não exclusivamente interessada ou partidária, mas sim moralizante. Os interesses do cronista não estão vinculados a uma estreita narração do passado - o contar 'o que realmente passou' -, mas sim à legitimação de uma ordem estabelecida em sua época, seja no âmbito moral, espiritual ou político. $^{2}$

A genealogia, gênero localizado entre o tempo pretérito ao qual fazia referência, estabelecendo um "início", e o tempo presente ao qual vinculava este passado, era intencionalmente heterogênea, pois muitos estudos sobre a historiografia medieval

\footnotetext{
${ }^{1}$ GUENÉE, Bernard. Les généalogies entre l'histoire et la politique: la fierté d'être Capétien en France au Moyen Âge, Annales. Économies, Sociétés, Civilisations, n. ${ }^{\circ} 33$, p. 450-477, 1978; SPIEGEL, Gabrielle M. Genealogy: Form and Function in Medieval Historical Narrative, History and Theory, Vol. 22, n. ${ }^{\circ}$ 1, p. $43-$ 53, 1983.

${ }^{2}$ AURELL, Jaume. La historiografía medieval: siglos IX-XV. In: Comprender el pasado. Una historia de la escritura y el pensamiento histórico (Aurell, Jaume; Balmaceda, Catalina; Burke, Peter; Soza, Felipe). Madrid: Ediciones Akal, 2013, p. 95-142.
}

\section{4}


reconhecem que durante a composição de uma obra costumava-se recordar os acontecimentos do contexto de composição. ${ }^{3}$ Comentar sobre genealogia implica fazer referência à utilização da memória, e um dos feitos mais importantes para a utilização da memória no Medievo foi quando a mesma se transformou em dinástica, vinculou o passado ao presente e estabeleceu uma continuidade no tempo; consequentemente, adquiriu um aspecto não somente genealógico, mas também historiográfico. ${ }^{4}$

A utilização da genealogia ocorreu em diversos momentos do Medievo, e um deles foi durante o contexto da Guerra Civil Catalã , entre 1462 e 1472. Esta guerra se referia às origens do Compromisso de Caspe, ocorrido em 1412, um dos episódios mais importantes da história da Coroa de Aragão. Em 1410, após a morte do rei Martinho I de Aragão (1396-1410), o qual não deixou sucessor legítimo, a Coroa de Aragão ficou sem um representante real. A dinastia dos condes de Barcelona e reis de Aragão se acabara; não havia mais a possibilidade de sucessão dinástica. A solução encontrada pela Concórdia de Alcañiz foi a eleição, em 1412, de Fernando de Trastâmara, o primeiro desta dinastia a reinar na Coroa de Aragão, o qual foi reconhecido como Fernando I de Aragão (1412-1416) e como rei da coroa aragonesa.

Entretanto, aproximadamente cinquenta anos depois, esta eleição ainda seria contestada por vozes contrárias e o auge desta oposição foi a Guerra Civil Catalã (14621472). Como afirmam Manuel Dualde e José Camarena, o Compromisso de Caspe, que mudou a história da Coroa de Aragão, foi discutido por diversos autores, não somente a partir de uma perspectiva favorável, mas também contrária. ${ }^{5}$ Neste artigo, propomos

\footnotetext{
${ }^{3}$ SPIEGEL, Gabrielle M. History, Historicism, and Social Logic of the Text in the Middle Ages, Speculum, Vol. 65, n. ${ }^{\circ}$ 1, p. 59-86, 1990.

${ }^{4}$ BORDONE, Renato. Storiografia, genealogia e araldica. Usi i abusi, en: L'Identità genealogica $e$ araldica: fonti, metodologie, interdisciplinarità, prospettive (Atti del XXIII Congresso internazionale di scienze genealogica e araldica, Torino, Archivio di Stato, 21-26 settembre 1998), Roma: Ministero per i beni culturali e ambientali, Ufficio centrale per i beni archivistici, 2000, p. 505-514.

${ }^{5}$ Diversos autores discutiram este tema, um dos mais importantes sobre a história da Coroa de Aragão. ALVAR GARCÍA DE SANTA MARÍA. Crónica de Juan II. Biblioteca de Autores Españoles. Tomo LXVIII. Madrid, 1947; LORENZO VALLA. De rebus a Ferdinando Aragoniae rege gestis. Textos Medievales, 41. Valencia: Anúbar, 1970; PEDRO DE ARENYS. Chronicon Ordinis Praedicatorum ab anno 1340 usque ad 1415. Roma, 1900; GABRIEL TURELL. Recort Historial. Barcelona: Editorial Barcino, 1950; MARTÍN DE ALPARTILS. Chronica actitatorum temporibus domini Benedicti XIII. Padeborn, 1906; BERNAT BOADES. Libre dels feyts d'armes de Catalunya. Barcelona: Editorial Barcino (29, 45, 52, 60 i 61), 1929-1948; La fi del comte d'Urgell. Barcelona: Editorial Barcino, 1931. JERÓNIMO ZURITA. Anales de la Corona de Aragón. Ed. preparada por Angel Canellas López. Zaragoza: C. S. I. C, 1976-1980. MARTÍN DE VICIANA. Crónica de la Ciudad de Valencia. Valencia: Sociedad Valenciana de Bibliófilos, 1882; DIEGO MONFAR. Historia de los condes de Urgel. Colección de Documentos Inéditos del Archivo de la Corona de Aragón. Barcelona, 1853; BRAULIO FOZ. Memoria sobre el Parlamento de Caspe celebrado en 1412 por los Estados de la Corona de Aragón para la elección del rey.
} 
estudar o significado de um texto composto momentos antes da Guerra Civil Catalã, a cronologia genealógica presente no fólio $48 \mathrm{v}$ do manuscrito Y-III-5 da Real Biblioteca do Monasterio de San Lorenzo del El Escorial (RBMSLE), a qual apresenta uma genealogia dos condes de Barcelona e reis de Aragão, estabelecendo, portanto, um vínculo entre o passado desta dinastia e o presente do contexto de composição.

\section{A genealogia: textualização de um passado, representação de uma legitimação}

De acordo com Gabrielle M. Spiegel, o significado de uma genealogia estava vinculado aos aspectos de linearidade, poder e legitimação:

Written above all to exalt a line and legitimize its power, a medieval genealogy displays a family's intention to affirm and extend its place in political life. As genealogies were amplified in the course of the twelfth century, pushing out in every direction, filling in each sequence with more detail, adding names of younger sons, daughters, and ancestors not previously mentioned, the profile of the family tree became a skeleton of aristocratic society, revealing the multiple threads which crossed and recrossed, binding regional nobilities into ever more integrated congeries of family relations. Raised to the royal level, genealogy took on the overtones of a dynastic myth (...). But whether aristocratic or royal, genealogies were expressions of social memory and, as such, could be expected to have a particular affinity with historical thought, and, at least to a certain extent, to impose their consciousness of social reality upon those whose task it was to preserve for future generations images of society in the record of history-Cassiodorus's imagines historiarum. ${ }^{6}$

A textualização de uma genealogia significava legitimar uma existência dinástica. Implicava reconhecer a duração do poder de uma família no tempo, suas diversas sucessões dinásticas, sua continuidade e soberania vinculados a um território. Uma genealogia apresentava não somente um passado e um presente, mas, mais importante, a conexão entre ambos tempos em um mesmo contexto. Além disso, mesmo referindo-se a um passado, sua textualização expressava a memória contemporânea ao contexto de

Zaragoza, 1848-1850; FLORENCIO JANER. Examen de los sucesos y circunstancias que motivaron el Compromiso de Caspe, y juício crítico de este acontecimiento y de sus consecuencias en Aragón y en Castilla. Madrid: Real Academia de la Historia, 1855. Uma obra contemporânea que trata o assunto é VICENS I VIVES, J. Els Trastàmares. Barcelona: Editorial Vicens-Vives, 1961, p. 85-90.

${ }^{6}$ SPIEGEL, Gabrielle M. Genealogy: Form and Function in Medieval Historical Narrative..., op. cit., p. 4353. 
composição, a qual estava inserida e vinculada no objeto na qual a genealogia era representada. Uma das formas de escrita genealógica foram as listas de reis, as quais, principalmente na Antiguidade e no princípio do Medievo, eram uma forma de sincronizar datas de acordo com as diferentes práticas locais. ${ }^{7}$

A própria Bíblia, um dos principais textos constantemente utilizados durante o Medievo, apresenta um esquema sucessório cujo primeiro homem é Adão, e a influência deste objeto condicionou a composição de outras obras durante o Medievo. ${ }^{8}$ De todas as formas, as palavras de Bernard Guenée esclarecem o significado das genealogias e principalmente quando elas são utilizadas, ou seja, durante os tempos de crises políticas e de contestação de poderes, características do contexto da Guerra Civil Catalã entre 1462 e 1472:

D'un autre côté catalogues et généalogies ont un évident intérêt politique. Ils sont les garants de la légitimité. Le fait inscrire ou de retenir le nom un évêque ou un roi dans le catalogue est un acte politique qui reconnaît sa légitimité. Et en un temps où le sang fonde la légitimité le pouvoir un prince est autant plus assuré que sa généalogie est plus convaincante. Il est donc pas étonnant non plus que catalogues et généalogies se soient multipliés dans les temps de crises politiques et de pouvoirs contestés et enjeu est ici tel que on le comprend bien la vérité historique est sans doute pas toujours le premier souci de leurs auteurs? ${ }^{9}$.

A utilização deste gênero histórico está relacionada ao contexto de legitimação política por parte das diversas dinastias então em estado de formação no século XII no Ocidente medieval, também conhecidas como monarquias feudais. ${ }^{10}$ A utilização da genealogia serviu não somente para determinar e estabelecer a continuidade dinástica em sua relação com o passado, mas também legitimar as políticas empreendidas por parte das diversas dinastias então reinantes neste contexto. Havia, dessa forma, uma relação intrínseca entre a utilização deste gênero histórico e a nova visão da sociedade

\footnotetext{
${ }^{7}$ DUMVILLE, David. What is a Chronicle? In: The Medieval Chronicle. Vol. II. Edited by Erik Kooper. Amsterdam/Atlanta: Rodopi, 2002, p. 1-27.

${ }^{8}$ SHOPKOW, Leah. Dynastic History. In: Historiography in the Middle Ages (Deborah Mauskopf Deliyannis, Editor). Leiden/Boston: Brill, 2003, p. 217-248.

${ }^{9}$ GUENÉE, Bernard. Les généalogies entre l'histoire et la politique: la fierté d'être Capétien en France au Moyen Âge, op. cit., p. 450-477.

${ }^{10}$ ROIGÉ, Prim Bertrán. Las monarquias feudales. In: Historia Universal. Edad Media. Director: Vicente Ángel Álvarez Palenzuela. Barcelona: Ariel, 2005, p. 453-464.
} 
aristocrática de então, cujo aspecto fundamental seria a continuação e manutenção da linhagem. De fato, a escolha do gênero histórico a ser produzido influenciava no conteúdo e também na mensagem que se desejava que fosse transmitida. Havia uma relação entre a forma de representação do passado e a mensagem a ser transmitida. No caso genealógico, o que se destaca é o aspecto político do mesmo, uma vez que havia um processo de tentativa de legitimação do presente através de uma aproximação ao passado. Além disso, uma das características mais destacadas deste contexto é o uso do passado, através de uma manipulação moralizante. ${ }^{11}$

\section{O manuscrito Y-III-5 da RBMSLE}

O fato de que não exista nenhuma informação específica sobre os copistas das diferentes partes deste manuscrito - as quais apresentaremos a seguir - faz com que em nosso estudo destaquemos a análise interna das narrativas e a materialidade do mesmo, as quais nos fornecem informações que nos aproximam ao seu possível contexto de composição.

\subsection{O conteúdo textual do manuscrito Y-III-5 da RBMSLE}

O conteúdo textual do manuscrito Y-III-5 da RBMSLE pode ser dividido em quatro partes. A primeira parte contém o texto Sumari d'Espanya, com o título Historia de España y particularmente de la Corona de Aragon hasta el Rey Don Alonso el quinto sin nombre de auctor en lengua lemosina localizado entre os fólios 1r-46r. A segunda parte é um espaço em branco entre os fólios 46v e 48r. Considerando que não há nenhum traço ou uma linha que finalize o conteúdo da parte anterior (primeira parte), podemos supor que esta segunda parte provavelmente serviria como espaço para continuação da primeira parte. A terceira parte é uma cronologia genealógica, presente no fólio $48 \mathrm{v}$, que apresenta a sucessão dos condes de Barcelona como reis de Aragão desde o casamento entre Raimundo Berengário IV o Santo (1137-1162) e Petronilha de Aragão (1136-1173) até a morte de Carlos de Viana (1421-1461), com acréscimos textuais que não correspondem à época de composição da cronologia. Por fim, a última parte é um compêndio do Livro

\footnotetext{
${ }^{11}$ AURELL, Jaume. La historiografía medieval: siglos IX-XV, op. cit., p. 95-142.
}

\section{8}


dos Feitos do rei Jaime I, especificamente sobre a Conquista de Valencia o comentarios del rey don Jaime el conquistador sobre la misma conquista, localizado entre os fólios 49r e 68v. As diversas partes do manuscrito e suas características estão sistematizadas na tabela 1:

\section{Tabela 1}

Estrutura textual do manuscrito Y-III-5 da RBMSLE

\begin{tabular}{|l|l|}
\hline \multicolumn{1}{|c|}{ Partes do manuscrito Y-III-5 da RBMSLE } & Fólios \\
\hline Historia de España y particularmente de la Corona de Aragón hasta el Rey Don Alonso & $1 \mathrm{r}-46 \mathrm{r}$ \\
\hline Fólios em branco & $46 \mathrm{v}-48 \mathrm{r}$ \\
\hline Cronologia genealógica dos condes de Barcelona e reis de Aragão & $48 \mathrm{v}$ \\
\hline Conquista de Valencia o comentarios del rey don Jaime el Conquistador & $49 \mathrm{v}-68 \mathrm{v}$ \\
\hline
\end{tabular}

\subsection{A estrutura paleográfica do manuscrito Y-III-5 da RBMSLE}

As informações paleográficas contidas neste manuscrito também são diversas. Basicamente, identificamos a presença de quatro copistas em sua composição, dos quais dois são principais e dois são secundários. O primeiro copista compôs os fólios 1r-46r; já o segundo copista continuou o trabalho desde o fólio 48v até o fólio 68v. Além disso, na terceira parte textual do manuscrito Y-III-5 (ver tabela 1) há a presença de dois copistas secundários, que realizaram algumas intervenções no final da cronologia genealógica presente no manuscrito, exatamente nos anos 1462 e 1468 . Também deve ser destacado que há diversas intervenções breves e acréscimos feitos nas margens de diversos fólios do manuscrito. Todas estas informações estão sistematizadas na tabela a seguir (tabela 2):

Tabela 2

Estrutura paleográfica do manuscrito Y-III-5 da RBMSLE

\begin{tabular}{|c|c|c|}
\hline Partes do manuscrito Y-III-5 da RBMSLE & Fólios & Copistas \\
\hline $\begin{array}{l}\text { Historia de España y particularmente de la Corona de Aragón hasta el } \\
\text { Rey Don Alonso }\end{array}$ & $1 \mathrm{r}-46 \mathrm{r}$ & Copista 1 \\
\hline Fólios em branco & $46 \mathrm{v}-48 \mathrm{r}$ & \multirow{3}{*}{$\begin{array}{l}\text { Copista } 2 \\
\text { (mais dois } \\
\text { copistas } \\
\text { secundários) }\end{array}$} \\
\hline Cronologia genealógica dos condes de Barcelona e reis de Aragão & $48 \mathrm{v}$ & \\
\hline Conquista de Valencia o comentarios del rey don Jaime el Conquistador & $49 v-68 v$ & \\
\hline
\end{tabular}




\subsection{As informações codicológicas do manuscrito Y-III-5 da RBMSLE}

Continuando com a diversidade de composição apresentada nos âmbitos textual e paleográfico, os aspectos codicológicos deste manuscrito também apresentam uma complexidade quando analisados. Como podemos ver na tabela 3, existem dois tipos de filigranas presentes no manuscrito, as quais, pelas boas condições materiais do objeto, foram identificadas como as de registro 3985 e 11664 de acordo com o catálogo de Briquet, datadas respectivamente em 1473 e $1476 .^{12}$

Tabela 3

Estrutura codicológica do manuscrito Y-III-5 da RBMSLE

\begin{tabular}{|l|l|l|}
\hline Filigrana & Ano & Fólios \\
\hline 3985 & 1473 & $6,7,10,12,13,15,16,19,22$ e 31 \\
\hline 11664 & 1476 & $24,40,44,46,47,48,49,52,54,58,60,63$ \\
\hline
\end{tabular}

Estas datas indicam que o manuscrito Y-III-5 da RBMSLE foi composto, portanto, no contexto do reinado de João II (1458-1479) e, especificamente, no contexto posterior ao da Guerra Civil Catalã (1462-1472), levando em consideração a perspectiva codicológica.

Entretanto, considerando as informações sobre as datas encontradas na terceira parte textual do manuscrito (1462 e 1468), devemos observar a da morte de Carlos de Viana apresentada na cronologia (23 de setembro de 1461), como veremos mais adiante. Logo, tais informações nos fariam localizar a composição do manuscrito, aproximadamente, entre os anos 1458-1461. Porém, se considerarmos os anos 1458-1461 como anos de composição, entraríamos em contradição com os anos encontrados no que diz respeito à perspectiva codicológica do objeto, ou seja, como destacamos acima, os anos de 1473 e 1476. Tal impasse é resolvido levando em consideração alguns aspectos particulares da codicologia: a diferença entre a composição textual (1458-1461) e a composição material (1473-1476) do manuscrito Y-III-5 da RBMSLE é explicada porque as filigranas servem para delimitar o tempo da produção do manuscrito, e, portanto, situam e aproximam o contexto de composição, mas não são definitivas sobre a datação,

12 BRIQUET, Charles M. Les filigranes: dictionnaire historique des marques du papier. Dès leur apparition vers 1282 jusqu'en 1600. Amsterdam: The Paper Publications Society, 1968. 
como nos lembra Lenka Horakova. ${ }^{13}$ Além disso, uma vez identificados os fólios que apresentam as filigranas, podemos observar que há uma certa divisão em sua composição material, já que praticamente os dois tipos de filigranas estão separados (com a exceção dos fólios 24 e 31 ).

\subsection{A intencionalidade do manuscrito Y-III-5 da RBMSLE}

Após apresentar as informações textuais, paleográficas e codicológicas do objeto e analisá-las conjuntamente, podemos afirmar que o manuscrito possui diferentes intencionalidades em suas partes destacadas. A primeira parte, na qual a cidade de Barcelona é a protagonista da narrativa, foi provavelmente composta por um copista que desejava destacar a importância da nobreza barcelonesa na formação histórica da cidade de Barcelona. ${ }^{14}$

Sobre a segunda parte, representada pelos fólios em branco, podemos supor que o copista da primeira parte tinha a intenção de preenchê-los com os acontecimentos do reinado de Afonso V o Magnânimo e possivelmente com os fatos do início do reinado de João II. Nossa afirmação tem como base duas características encontradas na datação da cronologia dos condes de Barcelona, onde é destacada a data da morte de Carlos de Viana (23 de setembro de 1461), e também pelo fato de que não há nenhum sinal, traço ou linha que indique a finalização do texto da primeira parte, o que nos permite, inicialmente, supor que este primeiro texto seria continuado nos fólios em branco.

Com referência à cronologia genealógica, ou seja, à terceira parte do manuscrito, esta nos indica claramente a preferência política do seu copista por Carlos de Viana, já que destaca que este personagem morreu "santo". Como destacamos, esta parte do manuscrito é importante para fornecer informações sobre o momento de sua composição.

No que se refere à última parte, composta também pelo copista da cronologia genealógica, há um compêndio sobre a conquista de Valência pelo rei Jaime I,

\footnotetext{
13 "Paper was originally made from cotton or linen rags, sometimes other materials were also added. Paper was manufactured in papermills. Each papermill had its own sign which they incorporated in the paper during its production and which enables us to identify the particular papermill and the approximate period (decades) of its production according to the paper. The signs are called watermark." HORAKOVA, Lenka. The Origin of Medieval Manuscripts Mainly in the Czech Lands. Dergimizin Yayinlanan Sayilari, n. ${ }^{\circ}$ 10, v. 2, p. 59-66, 2008.

${ }^{14}$ Sumari d'Espanya per Berenguer de Puigpardines. Edició a cura de Joan Iborra. Universitat de València: Servei de Publicacions de la Universitat de València, 2000, p. 7-30.
} 
acrescentando três informações que não constam nos objetos da tradição textual do Livro dos Feitos anteriores a este manuscrito: ${ }^{15}$ 1) a manifestação da participação dos nobres e dos cavaleiros no momento da organização da conquista de Valência; 2) a aparição de São Miguel - o qual muitas vezes era associado a São Jorge - como arcanjo e capitão do exército cristão e; 3) mediante uma omissão textual, estabelece a fala de Raimundo Berengário d'Ager, que no texto deve ser compreendido como Raimundo Berengário IV, já que o sobrenome "Ager" é omitido", ${ }^{16}$ príncipe de Aragão e conde de Barcelona, o agradecimento que o rei Jaime deveria fazer por tudo que Deus havia fornecido a ele e a sua linhagem. Esta omissão encontrada significa, em nossa opinião, que o copista da terceira parte "recuperou" dois passados (o de Raimundo Berengário IV e o de Jaime I) e estabeleceu-os no seu contexto político.

\section{Uma manifestação contrária ao Compromisso de Caspe?}

Uma cronologia representa os feitos que ocorreram em um determinado espaço e tempo e significa, principalmente, uma continuidade, ou seja, algo que se manteve no tempo. Além disso, não podemos esquecer que o caso que analisamos não se refere à origem da utilização da genealogia, mas sim que faz referência a outro momento em que a utilização genealógica era um fenômeno cultural em toda a Europa. ${ }^{17}$ No caso da terceira

\footnotetext{
${ }^{15}$ Nos referimos ao manuscrito 1 da Biblioteca de la Universitat de Barcelona e ao manuscrito 1734 da Biblioteca de Catalunya, os quais, nesta parte da narrativa, não omitiram o sobrenome "Ager", logo após "Ramon Berenguer", como podemos ver na próxima nota.

16 "E fet aço, enviam per los arquebisbes de Narbona e als bisbes e richs homens, e dixem-los com Jesus nostre senyor nos havia fet molta gracia en nostre govern e ara no se'n hauia feta una molt especial que tots la y deuem molt agrair, per quals feyem a saber per lur alegria com Valencia era nostra. E oit aço dom Nuno, e dom Eximen d'Urrea, e dom Pero Ferrandes de Çagra e dom Pero Cornell perderem la color de la cara com si hom los agues ferit dins lo cor, e no y ague om nat ques digues que u agrayssem a Jesus sino fon per lo arquebisbe e bisbes quens dixerem: 'Aço es obra de Jesus e yo no crech que aço no sia una de tres coses, ço es, o que vos auets seruit a Jesus ho que ara lo seruirets o qual seruireu'. E dit aço pels bisbes, dixerem nos los altres: ‘Com anaua aquesta faena?' E nos dixem-los que hauiem guiat Zaen rey de Valencie e tots los sarrayns de la ciutat que vagem guiats tro a Cullera e Denia ab lo que se'n poriem portar a les costes e hauiem nos abuydar la ciutat dins .V. dies. E llauos dixerem nos que u hauiem per bo, e dix en Ramon Berenguer: 'Molt ho deueu agrair a Jesus la amor que us mostra car lo que per vostre linatge e per vos s'es desitjat que s cumpla ara per vos. E lavors loamne nostre senyor deu Jesuscrist e la sua mare benyta"'. Real Biblioteca do Monasterio de San Lorenzo de El Escorial, códice Y-III-5, fol. 68r-68v.

${ }^{17}$ BORDONE, Renato. Storiografia, genealogia e araldica. Usi i abusi, op. cit., p. 505-514.
}

\section{2}


parte do manuscrito Y-III-5 da RBMSLE, a cronologia genealógica apresenta a genealogia dos condes de Barcelona como reis de Aragão:

Aquests són estats los reys d'Aragó depuix que l'egregi baró en Ramon Berenguer derrer pres la filla del rey Remiro de Aragó per muller.

Aquest En Ramon Berenguer, mentre visqué ab sa muller, filla del damunt dit rey Remiro, se intitulà príncep de Aragó e compte de Barcelona, però lo primer fill que nasqué de aquests dos se intitulà rey d'Aragó e compte de Barcelona. E aquests dos procrearen en fill primer Ildefonsus, del qual són proceïts per orde tots los gloriosos reys segons dejús apar.

Ildefonsus, agué fill

Pere, aquest agué fill Jaume, aquest agué fill

Pere, aquest agué fill

Alfonso, aquest agué fill

Jaume, aquest agué fill

Amphós, aquest agué fill

Pere, aquest agué fill

Johan, aquest agué fill jermà

Martí, aquest agué nebot

Ferrando, aquest agué fill

Alfonso, aquest agué jermà

Johan, aquest agué fill [apelat Carles] lo qual fon perseguit [ $e$ empresonat en lo castell de Morella] per lo pare e morí sant [en Barcelona]. Per lo qual se seguí gran roüna en lo Principat de Quatalunya perquè lo rey don Johan, pare del dit Carles, meté lo comte de Foix, són gendre, ab ben XM francesos e asetgà Barcelona per ben XV jorns. E estant sobre lo setge, los barceloneses alçaren banderes de rey de Castella apelat don Enric e donaren-se a ell. E fon en l'any 1462. Enaprés fon fet compromís per lo rey don Johan e los quatalans en poder del rey de Castella e del rey de Francia. E aquests pronunciaren que los quatalans eren bons e leals e que.s poguessen donar al senyor que.s volguessen. E prometeren los dits reys de Castella e de França que no ajudarien al rey don Johan ni als quatalans. En pochs dies, los quatalans trameteren dos galeres en Portugal e portaren l'infant don Pedro, nét qui era del comte d'Urgell. E aquell levaren per lur rei e senyor, lo qual visqué molt poch en lo regne. E a pochs dies, los dits quatalans an pres per rey e senyor lo duch Johan, senyor de Masella, lo qual regna huy en lo Principat e fa la guerra contra lo nostre rey don Johan en l'any $\underline{1468 .}^{18}$

${ }^{18}$ Real Biblioteca do Monasterio de San Lorenzo de El Escorial, códice Y-III-5, fol. 48v. 
Como destacamos anteriormente, o copista que compôs o texto Sumari d'Espanya (primeira parte do manuscrito) não é o mesmo que compôs a genealogia dos condes de Barcelona e reis de Aragão (terceira parte) e o compêndio da conquista de Valência (quarta parte), estas duas certamente depois do ano 1461, já que a cronologia genealógica se acaba com a morte de Carlos de Viana no ano destacado (23 de setembro de 1461).

Analisando as diversas partes desta cronologia, desde o seu começo até a frase em negrito (e incluindo a mesma), a cronologia foi composta por um único copista. Além disso, no que se refere à frase em negrito devemos considerar que a mesma apresenta acréscimos feitos por outro copista, no caso acima apresentados entre colchetes ("[apelat Carles]”, “[e empresonat en lo castell de Morella]”, “[en Barcelona]”), já que a frase original era "Johan aquest agué fill lo qual fon perseguit per lo pare e morí sant" (no manuscrito analisado, os acréscimos entre colchetes encontram-se sobre a frase em itálico citada anteriormente). Ainda sobre a cronologia genealógica, a parte que está somente em itálico refere-se a um acréscimo realizado no ano de 1462. Por fim, a parte que está em itálico e sublinhada refere-se a outro acréscimo, provavelmente escrita em 1468. Tais acréscimos referem-se aos dois copistas secundários citados na tabela 2. Em uma consulta in situ ao manuscrito, podemos comprovar que os dois últimos acréscimos apresentavam tintas diferentes.

O que nos interessa nestas palavras é a frase original em negrito e que, de acordo com a nossa hipótese situaria todas as quatro partes do manuscrito aproximadamente em um contexto específico: “Johan aquest agué fill lo qual fon perseguit per lo pare e morí sant." Como vimos anteriormente, devemos recordar que esta frase foi composta pelo copista da terceira parte, ou seja, da cronologia genealógica. Estas palavras referem-se a João II de Aragão (“Johan") e ao seu filho Carlos de Viana ("fill”), fato que, pelo menos, situaria a composição da genealogia durante o reinado do primeiro personagem citado, João II de Aragão. Portanto, o copista desta cronologia, e consequentemente do compêndio da conquista de Valência, já que falamos da mesma pessoa (ver tabela 2), provavelmente era um partidário de Carlos de Viana, já que destacou a informação de que João II de Aragão perseguiu o seu filho o qual morreu "santo".

Além disso, como vimos anteriormente, se considerarmos que os acréscimos posteriores, os quais estão relacionados aos anos de 1462 e 1468 foram escritos por dois

\section{4}


outros copistas (a análise paleográfica nos indica duas mãos diferentes e duas tintas diferentes), veremos que suas informações reforçam a hipótese de que o copista da cronologia era favorável à posição política de Carlos de Viana, e consequentemente contrário ao seu pai, João II de Aragão. Neste sentido, as informações encontradas no manuscrito Y-III-5 fazem com que o mesmo seja entendido como um locus no qual se entrecruzam diversas intencionalidades - já que falamos de diferentes copistas - as quais foram formuladas com o passar do tempo.

Considerando a trajetória do Principado da Catalunha contra os reis Trastâmaras, desde a decisão tomada em 1412 até a Guerra Civil Catalã (1462-1472), podemos afirmar que este provável partidário de Carlos de Viana e copista da cronologia genealógica, aproveitando as informações encontradas na primeira parte do manuscrito aqui destacada, manifestou sua preferência política não somente mediante a composição do compêndio da conquista de Valência (quarta parte do manuscrito), mas também estabeleceu um vínculo entre o passado e o presente mediante a formulação da cronologia genealógica (terceira parte), a qual finalizava com a presença de Carlos de Viana e a informação de sua morte "santa". Além disso, podemos compreender esta cronologia como uma finalização da dinastia Trastâmara, já que, com a morte de Carlos de Viana, o copista não estabelece a continuidade da mesma, possibilitando outras informações que provavelmente lhe seriam contemporâneas. Anos mais tarde este espaço foi preenchido pelas informações dos copistas do ano 1462 e do ano 1468.

Considerando a data de composição da cronologia como posterior à morte de Carlos de Viana, ou seja, 23 de setembro de 1461, o herdeiro de João II, o infante Fernando, que futuramente seria Fernando II de Aragão, já havia nascido (10 de março de 1452). A omissão desta informação na continuação da cronologia é suficiente para provar que o copista da terceira parte do manuscrito Y-III-5 do RBMSLE era contrário, portanto, à presença do infante Fernando como futuro sucessor do trono da Coroa de Aragão, o que reforça a hipótese do seu apoio político a Carlos de Viana. Neste sentido, podemos afirmar que, ao aproveitar os dados existentes na primeira parte do manuscrito, o copista da terceira parte, provável partidário de Carlos de Viana, de acordo com os seus objetivos, alterou o estilo (forma) da redação da primeira parte do manuscrito formulando esta cronologia, a qual refletia o seu pensamento sobre os acontecimentos do seu contexto atual, recuperando, assim, o começo da dinastia iniciado pelos condes de Barcelona e reis

\section{5}


de Aragão ("Ildefonsus") até o começo da dinastia dos Trastâmaras na Coroa de Aragão ("Johan").

O motivo pelo qual afirmamos que esta cronologia é contrária ao Compromisso de Caspe refere-se ao fato de que a mesma não somente manifesta a morte "santa" de Carlos de Viana pelo seu pai, João II de Aragão - o qual, de acordo com o resultado de 1412, naquele momento era o continuador da decisão de Caspe -, mas também porque não apresenta informações sobre a continuidade da dinastia em um contexto no qual o sucessor (Fernando II de Aragão) já havia nascido (10 de março de 1452). Neste sentido, devemos entender este manuscrito a partir de sua perspectiva holística, considerando todos os aspectos destacados, interpretando-o como uma "total unit":

During the past two generations, codicology and palaeography have become immensely refined disciplines and have produced new bodies of information that would rightly be the envy of our elders. In contrast to them, we can no longer consider a codex as a mere receptacle that happens to have preserved the text under investigation; instead, a modern editor will have to look at the manuscript 'holistically', as a total unit about whose physical makeup, composition, and history he or she will want to know as much as possible. ${ }^{19}$

Como afirmamos anteriormente, o Compromisso de Caspe, estabelecido no ano 1412, foi discutido diversas vezes ao longo dos séculos. ${ }^{20}$ Neste sentido, e considerando como ponto principal os problemas entre João II de Aragão e Carlos de Viana sobre se a "primogenitura universal" deveria ser atribuída a Carlos de Viana, devemos considerar três razões destacadas por Vicens Vives para o não estabelecimento da "primogenitura": 1) o fato de que a primogenitura implicava na constituição de uma corte de governo e jurisdição específica; 2) o desejo de João II de controlar as atividades de Carlos inserindoo no âmbito político português; 3) a intenção de João II de dar continuidade à sua dinastia levando ao trono o seu filho Fernando.

Além disso, ao levar seu filho Carlos de Viana para a prisão, o que provocou a sua morte, João II recebeu a resposta dos dirigentes do Principado da Catalunha,

\footnotetext{
${ }^{19}$ WENZEL, Siegfried. Reflections on (New) Philology. Speculum 65/1 (1990), p. 11-18 (p. 14).

${ }^{20}$ CAMARENA, José y DUALDE, Manuel. El Compromiso de Caspe. Zaragoza: Institución "Fernando el Catolico", 1976, p. 263-279.
} 
representados pela aristocracia e pela $\mathrm{Biga}^{21}$ os quais reivindicavam seus direitos usurpados e também a "primogenitura universal" para Carlos. ${ }^{22}$ Mais adiante, estes grupos sociais, juntamente com os vianistas, formaram o "Conselho representante do Principado de Catalunha", momento no qual a cidade de Barcelona viveu dias de euforia revolucionária defendendo as leis da terra. Diante da negativa referente à primogenitura de Carlos de Viana, em fevereiro de 1461, o mesmo foi proclamado como herdeiro do Principado pelo "Conselho representante". ${ }^{23}$ Neste sentido, é crucial a afirmação de Vicens Vives sobre a imagem de Carlos de Viana como "santo" no Principado:

O desenvolvimento do regime constitucional estabelecido pela Capitulação de Vilafranca estava apoiado na pessoa do novo oficial real, convertido em herói popular, em símbolo de uma causa patriótica, no transcurso de poucos meses. Infelizmente, a experiência não pode ser feita. Carlos de Viana morria em Barcelona, a mesma cidade que havia recebido freneticamente, em 12 de março, de suas últimas fatigas, que pioraram a doença pulmonar que sofria. As pessoas com sentido - como o bispo João Margarit - considerou providencial este traspasso (23 de setembro de 1461). Os apressados escreviam necrologias delirantes, onde já se notava o mito de 'São Carlos de Catalunha'. Os sentimentais se dirigiam a sua tumba milagrosa. ${ }^{24}$

\section{Conclusão}

Inicialmente, poderíamos pensar que as diversas partes deste manuscrito não apresentariam nenhuma relação entre si e se referiam a contextos diferentes. Agora, depois de uma análise reunindo informações textuais, paleográficas e codicológicas e interpretando-as conjuntamente, podemos concluir que o manuscrito Y-III-5 da RBMSLE deve ser considerado como uma "unidade total", para usar o termo de uma perspectiva codicológica, para aproximar-se ao seu real significado, reproduzindo em seus fólios o

\footnotetext{
${ }^{21}$ SARASA, Esteban. "La Corona de Aragón en la baja Edad Media: de la plenitud mediterránea a las crisis acumulativas, mutaciones y reconstrucciones." In: IRADIEL, Paulino; MORETA, Salustiano; SARASA, Esteban. Historia Medieval de la España Cristiana. Madrid: Ediciones Cátedra, 1989, p. 642.

${ }^{22}$ VICENS I VIVES, J. Els Trastàmares. Barcelona: Editorial Vicens-Vives, 1961, p. 170.

${ }^{23}$ VICENS I VIVES, J. Els Trastàmares, op. cit., p. 172-173.

${ }^{24}$ VICENS I VIVES, J. Els Trastàmares. op. cit., p. 174-175.
} 
contexto anterior à Guerra Civil Catalã na qual o passado foi relembrado, manipulado e textualizado.

Além disso, devemos entender estas diferentes partes em um nível de complementação no que se refere às suas diferentes intencionalidades. A primeira parte (Sumari d'Espanya) destaca o protagonismo da cidade de Barcelona e a função histórica da dinastia dos condes de Barcelona na formação territorial deste condado. A quarta parte, o compêndio da conquista de Valência do Livro dos Feitos de Jaime I, recorda a importância dos nobres na conquista do território valenciano, já que relembra esta conquista feita pelo rei Jaime I e a afirmação de Raimundo Berengário IV mediante uma manipulação deste compêndio. Entre estas duas partes encontramos a cronologia genealógica dos condes de Barcelona como reis de Aragão (terceira parte), cujo conteúdo apresenta desde o casamento entre Raimundo Berengário IV o Santo e Petronilha de Aragão até a morte "santa" de Carlos de Viana, e a intenção do copista que, cerca de cinquenta anos depois do Compromisso de Caspe, desejava não somente estabelecer uma continuidade entre o começo da dinastia dos condes de Barcelona como reis de Aragão de acordo com a posição política do copista - e a morte "santa" daquele que seria o próximo sucessor, mas também destacar o final da dinastia Trastâmara com a morte primogênito e herdeiro jurado, filho de João II de Aragão, Carlos de Viana. 